\title{
The dependence of Ni-Fe bioxide composites nanoparticles on the $\mathrm{FeCl}_{2}$ solution used
}

\author{
Yueqiang Lin, Jian Li*, Lihua Lin, Xiaodong Liu, Longlong Chen and Jun Fu
}

\begin{abstract}
Background: $\mathrm{Ni}_{2} \mathrm{O}_{3}-\gamma-\mathrm{Fe}_{2} \mathrm{O}_{3}$ composite nanoparticles coated with a layer of $2 \mathrm{FeCl} \cdot 5 \mathrm{H}_{2} \mathrm{O}$ can be prepared by co-precipitation and processing in $\mathrm{FeCl}_{2}$ solution. Using vibrating sample magnetometer (VSM), X-ray diffraction (XRD), transmission electron microscopy (TEM) and X-ray photoelectron spectroscopy (XPS) diffraction techniques, the dependence of the preparation on the concentration of the $\mathrm{FeCl}_{2}$ treatment solution is revealed.

Results: The magnetization of the as-prepared products varied non-monotonically as the $\mathrm{FeCl}_{2}$ concentration increased from $0.020 \mathrm{M}$ to $1.000 \mathrm{M}$. The Experimental results show that for the composite nanoparticles, the size of the $\gamma-\mathrm{Fe}_{2} \mathrm{O}_{3}$ phase is constant at about $8 \mathrm{~nm}$, the $\mathrm{Ni}_{2} \mathrm{O}_{3}$ phase decreased and the $2 \mathrm{FeCl}_{3} \cdot 5 \mathrm{H}_{2} \mathrm{O}$ phase increased with increasing concentration of $\mathrm{FeCl}_{2}$ solution. The magnetization of the as-prepared products mainly results from the $\gamma-\mathrm{Fe}_{2} \mathrm{O}_{3}$ core, and the competition between the reduction of the $\mathrm{Ni}_{2} \mathrm{O}_{3}$ phase with the increase of the $2 \mathrm{FeCl}_{3} \cdot 5 \mathrm{H}_{2} \mathrm{O}$ phase resulted in the apparent magnetization varying non-monotonically.

Conclusions: When the concentration of $\mathrm{FeCl}_{2}$ treatment solution did not exceed $0.100 \mathrm{M}$, the products are spherical nanoparticles of size about $11 \mathrm{~nm}$; their magnetization increased monotonically with increasing the concentration of $\mathrm{FeCl}_{2}$ solution due to the decreasing proportion of $\mathrm{Ni}_{2} \mathrm{O}_{3}$ phase.
\end{abstract}

Keywords: Composite, Nanoparticles, $\mathrm{FeCl}_{2}$ solution, Concentration

\section{Introduction}

Magnetic nanoparticles with diameters less than $100 \mathrm{~nm}$ have attracted increasing interest as particles in this size range may allow investigation of fundamental aspects of magnetic ordering phenomena in magnetic materials with reduced dimensions and could lead to new technological applications [1-5]. Studies of magnetic nanoparticles have focused on the development of novel synthetic methods [5]. A nanocomposite is a material composed of two or more phases, one of which has a grain size of less than $100 \mathrm{~nm}$. The combination of different physical or chemical properties may give rise to completely new materials [6,7]. It has been demonstrated that the formation of a passive coating of an inert material on the surface of iron oxide nanoparticles can help to improve their chemical stability and prevent their aggregation in liquids [8-11]. Recently, composite nanoparticles based on magnetic iron oxide have been prepared [12-16]. Such

\footnotetext{
* Correspondence: aizhong@swu.edu.cn

School of Physical Science \&Technology, MOE Key Laboratory on Luminescence and Real-Time Analysis, Southwest University, Chongqing 400715, People's Republic of China
}

magnetic nanocomposites have applications ranging from ferrofluids to separation science and technology [17].

In previous work, we described a method to prepare magnetic nanoparticles using a chemically induced transition $[15,16,18,19]$ and $\mathrm{Ni}-\mathrm{Fe}$ bioxide composite nanoparticles were prepared using this method. In the preparation, a precursor consisting of $\mathrm{FeOOH}$ wrapped in $\mathrm{Ni}(\mathrm{OH})_{2}$ was synthesized by the well-known coprecipitation method. Then, using heat treatment in $0.25 \mathrm{M} \mathrm{FeCl}_{2}$ solution at $100^{\circ} \mathrm{C}$, a transition took place in which in addition to the $\mathrm{Ni}(\mathrm{OH})_{2}$ partially dissolving, the $\mathrm{FeOOH} / \mathrm{Ni}(\mathrm{OH})_{2}$ precursor was transformed into $\gamma-\mathrm{Fe}_{2} \mathrm{O}_{3} / \quad \mathrm{Ni}_{2} \mathrm{O}_{3}$ composite nanoparticles coated with $\mathrm{FeCl}_{3}[15]$. The $\mathrm{Ni}_{2} \mathrm{O}_{3}$ is weakly ferromagnetic [16] and the $\mathrm{FeCl}_{3}$ is paramagnetic. Experiments have shown that such $\mathrm{Ni}$-Fe bioxide composite nanoparticles are very suitable for the synthesis of ferrofluids [20]. This chemically induced transition using $\mathrm{FeCl}_{2}$ solution may provide a new route for the preparation of oxide nanoparticles. In the present work, we have investigated the characteristics of Ni-Fe bioxide composite nanoparticles as a function of the concentration of $\mathrm{FeCl}_{2}$ treatment solution. 


\section{Experimental Preparation}

The preparation of the Ni-Fe bioxide composite nanoparticles was divided into two steps. Firstly, the precursor based on FeOOH wrapped with $\mathrm{Ni}(\mathrm{OH})_{2}$ was synthesized using the co-precipitation method, which has been described in detail elsewhere [15,21]. The second step was to add the precursor to $\mathrm{FeCl}_{2}$ solution, using concentrations of $0.025 \mathrm{M}, 0.050 \mathrm{M}, 0.075 \mathrm{M}$, $0.100 \mathrm{M}, 0.125 \mathrm{M}, 0.250 \mathrm{M}, 0.500 \mathrm{M}, 0.750 \mathrm{M}$ and $1.000 \mathrm{M}$, to obtain $400 \mathrm{ml}$ of the mixed solution. Then this solution was heated to boiling point for $30 \mathrm{~min}$ in atmosphere; the nanoparticles precipitated gradually after the heating had stopped. Finally, these particles were dehydrated with acetone and allowed to dry naturally.

\section{Characterization}

A series of $\mathrm{Ni}-\mathrm{Fe}$ oxide composite nanoparticles was prepared by a chemically induced transition involving $\mathrm{FeCl}_{2}$ solution. The dependence on the concentration of the $\mathrm{FeCl}_{2}$ solution was investigated by measuring the specific magnetization curves of the samples at room
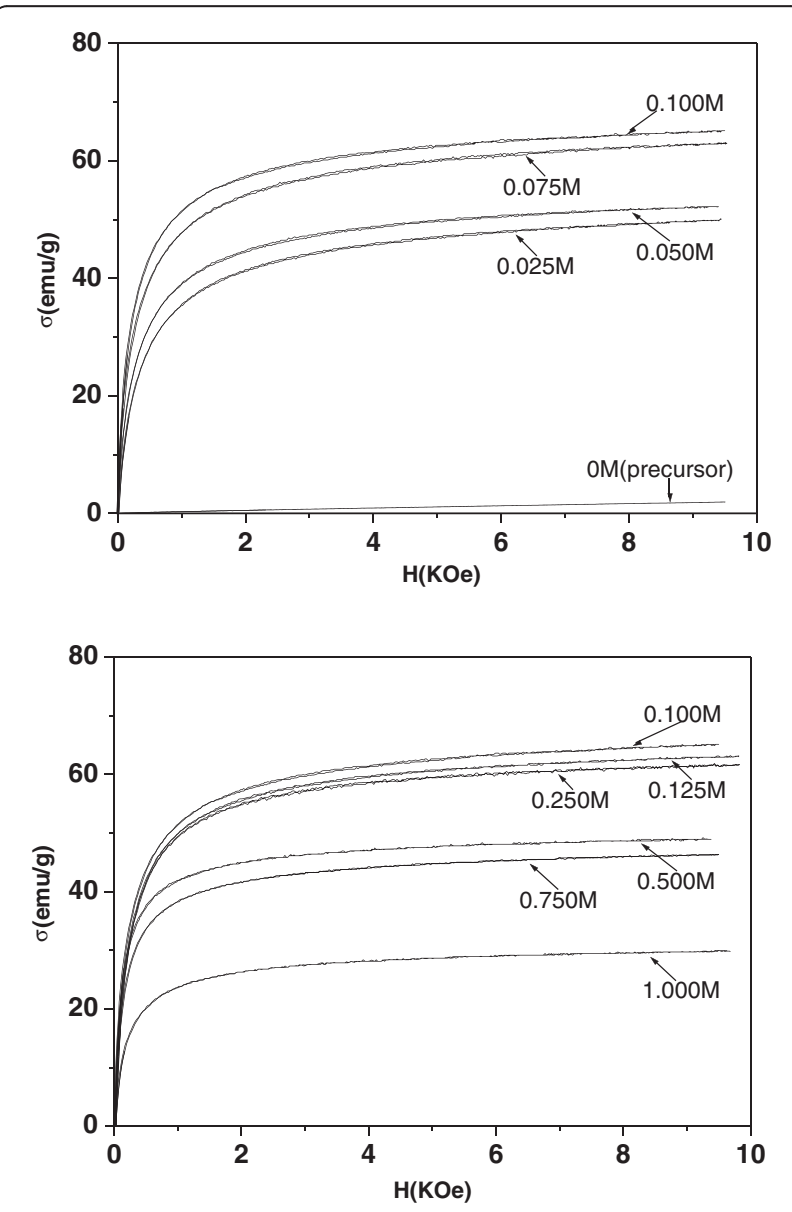

Figure 1 Specific magnetization curves for the samples. temperature using a vibrating sample magnetometer (VSM, HH-15, applied field up to $10^{4}$ Oe).

The samples were prepared using $\mathrm{FeCl}_{2}$ solutions $0.025 \mathrm{M}, 0.075 \mathrm{M}, 0.100 \mathrm{M}, 0.125 \mathrm{M}$ and $0.500 \mathrm{M}$, which were named samples (1), (2), (3), (4) and (5), respectively. In addition to the magnetic measurements, their crystal structures, morphology and chemical composition were analyzed by X-ray diffraction (XRD, XD-2, $\mathrm{Cu} \mathrm{K} \alpha$ radiation), transmission electron microscopy (TEM, JEM-2100F, at $100 \mathrm{kV}$ ) and X-ray photoelectron spectroscopy (XPS, Thermo ESCA250, Mg target).

\section{Results and analysis}

Figure 1 shows the specific magnetization curves of the samples. Clearly, all samples exhibited ferromagnetic features, with their specific magnetization varying nonmonotonically with the concentration of $\mathrm{FeCl}_{2}$ solution. At first, the magnetization strengthened as the $\mathrm{FeCl}_{2}$ concentration increased from $0.025 \mathrm{M}$ to $0.100 \mathrm{M}$, then the magnetization weakened as the concentration increased from $0.100 \mathrm{M}$ to $1.000 \mathrm{M}$.

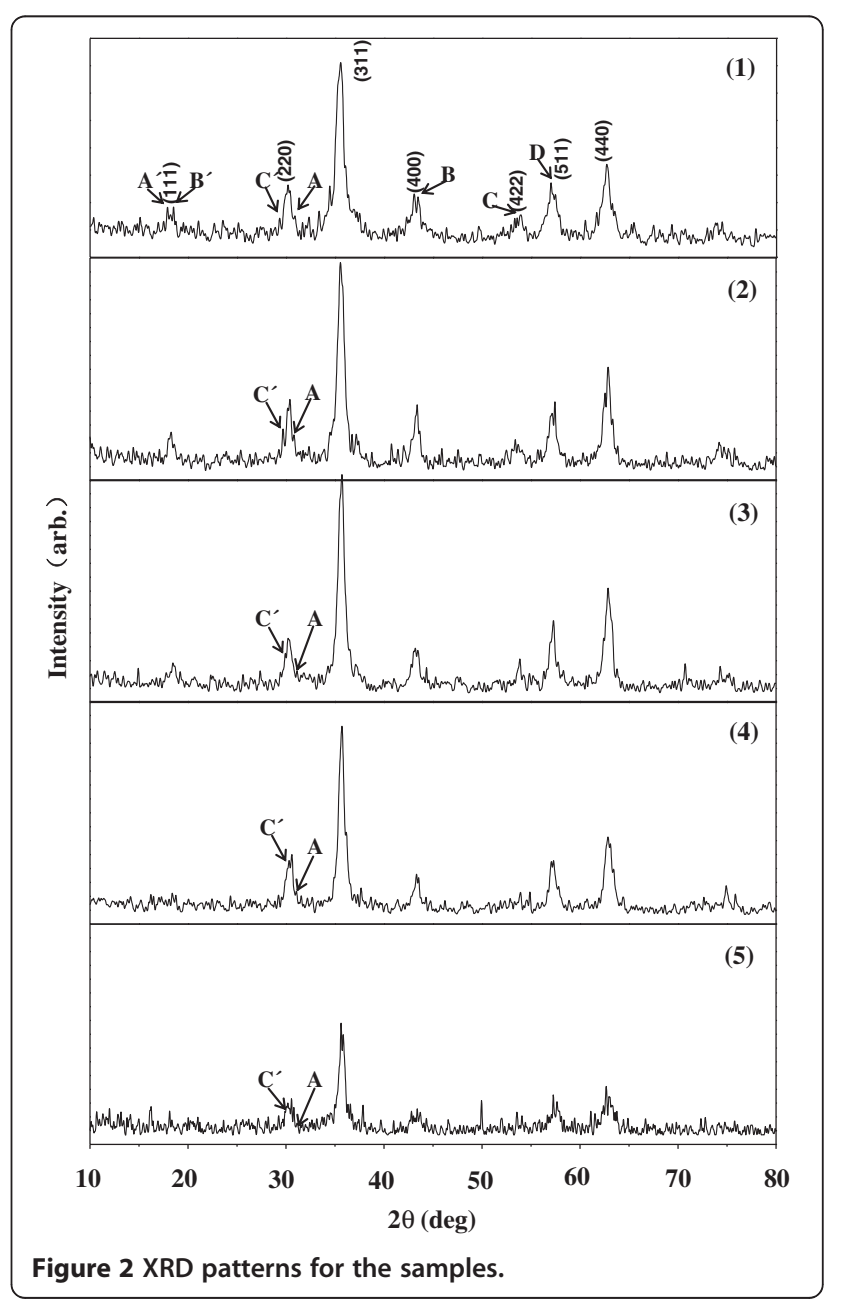


The XRD patterns of the samples are shown in Figure 2. The results show that these samples contain mainly $\gamma-\mathrm{Fe}_{2} \mathrm{O}_{3}$ with a trace of $\mathrm{Ni}_{2} \mathrm{O}_{3}$ and $2 \mathrm{FeCl}_{3} \cdot 5 \mathrm{H}_{2} \mathrm{O}$, as indicated by the arrows $\mathrm{A}, \mathrm{B}, \mathrm{C}$ and $\mathrm{D}$ for $\mathrm{Ni}_{2} \mathrm{O}_{3}$, and by arrows $\mathrm{A} /, \mathrm{B} / \mathrm{\text {and }} \mathrm{C} /$ for $2 \mathrm{FeCl}_{3} \cdot 5 \mathrm{H}_{2} \mathrm{O}$. For the ferrite nanoparticles, the grain sizes $d_{c}$ can be estimated from the half-maximum width of the (311) diffraction peak $\beta$ using Scherr's formula [22], $d_{c}=K \lambda / \beta \cos \theta$, where $K$ is a constant $0.89, \lambda$ is the $\mathrm{X}$-ray wavelength $(\mathrm{Cu}$ $\left.\mathrm{K}_{\alpha}=0.1542 \mathrm{~nm}\right)$ and $\theta$ is the Bragg diffraction angle of the (311) plane. The calculated results gave about the same value $8 \mathrm{~nm}$ for the $\gamma-\mathrm{Fe}_{2} \mathrm{O}_{3}$ grains in all the samples. In addition, comparing the intensity ratios of the A peak of $\mathrm{Ni}_{2} \mathrm{O}_{3}(\mathrm{~d}=0.2800 \mathrm{~nm})$ with the C'peak of $2 \mathrm{FeCl}_{3} \cdot 5 \mathrm{H}_{2} \mathrm{O}(\mathrm{d}=0.2980 \mathrm{~nm})$ show that the proportion of $\mathrm{Ni}_{2} \mathrm{O}_{3}$ was reduced and $2 \mathrm{FeCl}_{3} \cdot 5 \mathrm{H}_{2} \mathrm{O}$ increased as the concentration of the $\mathrm{FeCl}_{2}$ solution increased.

TEM observations of the samples are shown in Figure 3. These results show that the particles in samples (1), (2), (3) and (4) are nearly spherical, with an average particles size $d_{p}$ of about $11 \mathrm{~nm}$, but in sample(5) there are a few rod-shaped particles (shown in the insert) in addition to the spherical particles. Clearly, the size of the spherical particles in sample(5) is less than those of samples (1), (2), (3) and (4), and is about $8 \mathrm{~nm}$. High-resolution TEM results reveal that the particles have core-shell structure, as Figure 4 shown.

XPS measurements confirmed that there were $\mathrm{Fe}, \mathrm{O}$, $\mathrm{Ni}$ and $\mathrm{Cl}$ in the samples as illustrated in Figure 5. By

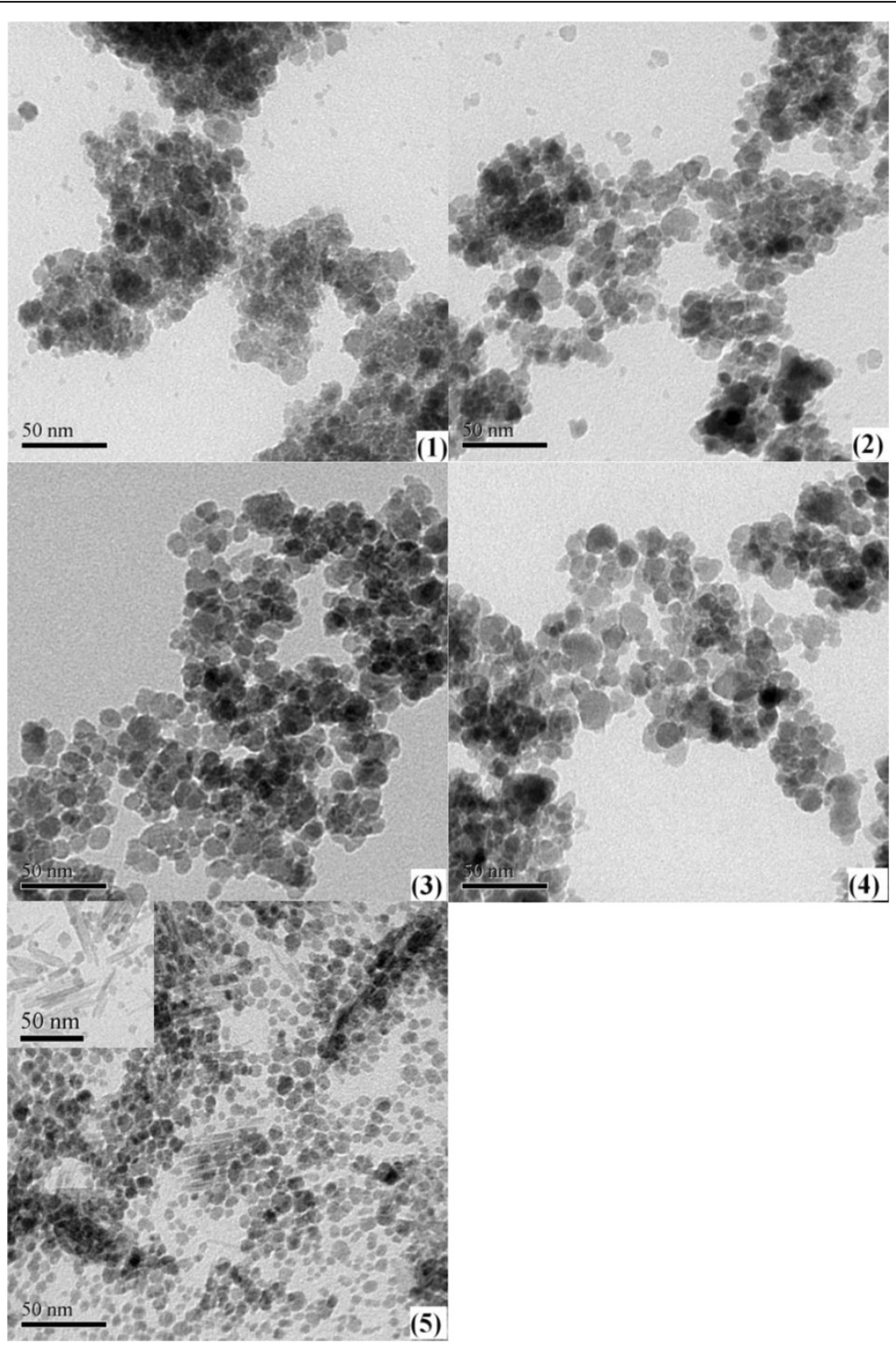

Figure 3 TEM images for the samples. 


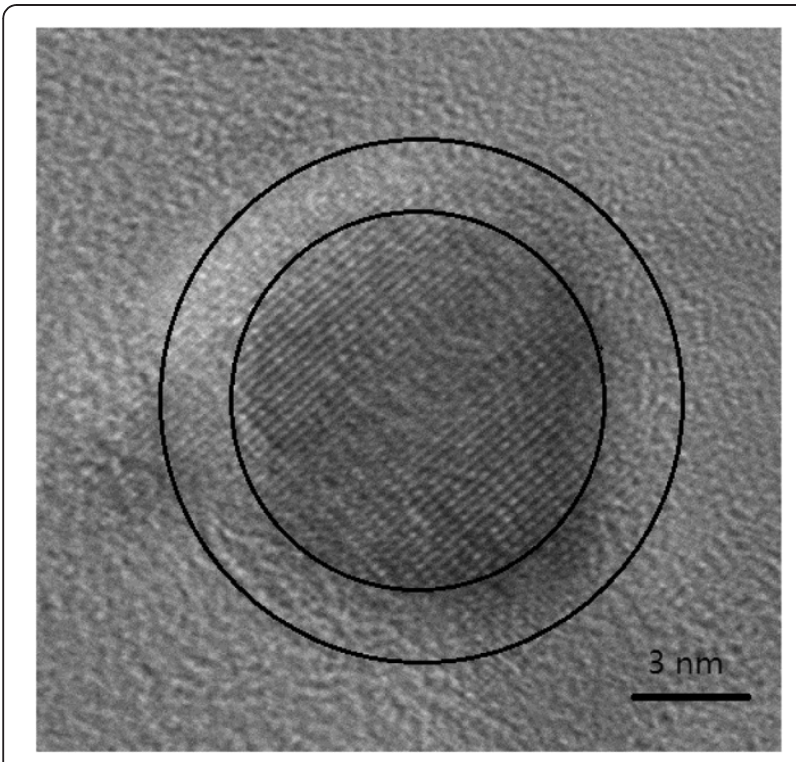

Figure 4 High-resolution TEM image of the particle from sample (3).

analysis of the binding energies in the spectra, it can be deduced that the samples consisted of $\mathrm{Fe}_{2} \mathrm{O}_{3}, \mathrm{Ni}_{2} \mathrm{O}_{3}$ and $\mathrm{FeCl}_{3}$. The binding energy data are listed in Table 1. A quantitative analysis shows that for samples (1), (2), (3) and (4), the ratio $\mathrm{Ni}: \mathrm{Cl}$ decreased in that order, the ratio Fe:Ni clearly increased and the ratio $\mathrm{Fe}: \mathrm{Cl}$ increased slightly. For sample (5), the ratio $\mathrm{Fe}: \mathrm{Cl}$ was clearly lower than that for sample (4), along with the ratio $\mathrm{Ni}: \mathrm{Cl}$, The ratio Fe:Ni was, however, higher. The complete data are listed in Table 2. In conclusion, it can be determined that for all the samples, the proportion of $\mathrm{Ni}_{2} \mathrm{O}_{3}$ phase decreased and $\mathrm{FeCl}_{3}$ phase increased as the concentration of $\mathrm{FeCl}_{2}$ solution increased. This also agrees with the XRD results.

\section{Discussion}

The results show that in the preparation of $\mathrm{Ni}$-Fe bioxide nanoparticles, when the concentration of $\mathrm{FeCl}_{2}$ solutions were less than $0.5 \mathrm{M}$, the samples (1), (2), (3) and (4) were single spherical particles consisting of a $\gamma-\mathrm{Fe}_{2} \mathrm{O}_{3}$ core, $\mathrm{Ni}_{2} \mathrm{O}_{3}$ outside the core and with an outermost layer of $2 \mathrm{FeCl}_{3} \cdot 5 \mathrm{H}_{2} \mathrm{O}$. However, when the concentration reached $0.5 \mathrm{M}$, sample (5) formed rod-shaped particles together with spherical particles than smaller those of samples (1), (2), (3) and (4).

For samples (1), (2), (3) and (4), the results of both XRD analysis and TEM observations indicated that the $\gamma-\mathrm{Fe}_{2} \mathrm{O}_{3}$ grain size and the size of the complete particles remain about constant. However, the XPS results showed that the proportion of $\mathrm{Ni}_{2} \mathrm{O}_{3}$ decreased and $\mathrm{FeCl}_{3}$ increased smoothly. This suggests that over the XPS detection range $d_{x}$ determined by the mean free paths of the electrons detected [23,24] and which is about $3 \mathrm{~nm}$, the volume fraction of the $\gamma-\mathrm{Fe}_{2} \mathrm{O}_{3}$ phase remained constant(i.e. diameter of $\gamma-\mathrm{Fe}_{2} \mathrm{O}_{3}$ core $d_{r}$ can be regarded as constant), as did the sum of the volume fractions of $\mathrm{Ni}_{2} \mathrm{O}_{3}$ and $2 \mathrm{FeCl}_{3} \cdot 5 \mathrm{H}_{2} \mathrm{O}$, whose detection ranges are $\mathrm{d}_{\mathrm{Ni}}$ and $\mathrm{d}_{\mathrm{Cl}}$, respectively. So, from samples (1) to (4), the reduction of $\mathrm{Ni}$ species and the increase of $\mathrm{Cl}$ species in the XPS results corresponds to the variation of the volume fraction, a thinning of the $\mathrm{Ni}_{2} \mathrm{O}_{3}$ layer and a thickening of the $2 \mathrm{FeCl}_{3} \cdot 5 \mathrm{H}_{2} \mathrm{O}$ layer. This is also in agreement with the clear increase of the Fe:Ni ratio and the slight increase of the $\mathrm{Fe}: \mathrm{Cl}$ ratio as the concentration of $\mathrm{FeCl}_{2}$ solution increases. Since samples (1), (2), (3) and (4) consist of spherical particles and the measured XPS depth $d_{x}$ is greater than the combined thickness of $\mathrm{Ni}_{2} \mathrm{O}_{3}\left(\mathrm{~d}_{\mathrm{Ni}}\right)$ and $\mathrm{FeCl}_{3}\left(\mathrm{~d}_{\mathrm{Cl}}\right)$, as shown in Figure 6, the measured atomic ratio between $\mathrm{Ni}$ and $\mathrm{Cl}$ species $\mathrm{Ni} / \mathrm{Cl}$ allows the molar ratio between $\mathrm{Ni}_{2} \mathrm{O}_{3}$ and $\mathrm{FeCl}_{3}$ to be deduced as $\mathrm{Ni}_{2} \mathrm{O}_{3} / \mathrm{FeCl}_{3}=1.5 \mathrm{Ni} / \mathrm{Cl}$. The results are also listed in Table 2.

For sample (5), the results from both the XRD analysis and TEM observations show that the $\gamma-\mathrm{Fe}_{2} \mathrm{O}_{3}$ grain size is the same and the particles size is less than the samples (1), (2), (3) and (4), and the both sizes are about the same. Since there is much less Ni species than $\mathrm{Fe}$, it is concluded that the spherical particles could consist of a $\gamma-\mathrm{Fe}_{2} \mathrm{O}_{3}$ core and $\mathrm{a}_{2} \mathrm{Ni}_{3}$ surface layer. The average particle size depends mainly on the $\gamma-\mathrm{Fe}_{2} \mathrm{O}_{3}$ phase, and the rod-shaped particles may consist of crystals of $2 \mathrm{FeCl}_{3} \cdot 5 \mathrm{H}_{2} \mathrm{O}$. This is also in agreement with the $\mathrm{Fe}: \mathrm{Cl}$ ratio for samples (1) to (4) which shows a decrease rather than an increase.

In summary, as the concentration of $\mathrm{FeCl}_{2}$ solution used for the chemically induced transition increases, the samples retain a constant $\gamma-\mathrm{Fe}_{2} \mathrm{O}_{3}$ composition but the proportion of $\mathrm{Ni}_{2} \mathrm{O}_{3}$ is reduced and that of $2 \mathrm{FeCl}_{3} \cdot 5 \mathrm{H}_{2} \mathrm{O}$ increases. Clearly, the non-monotonic variation of the specific magnetization of the samples as a function of $\mathrm{FeCl}_{2}$ concentration can be attributed to the phase changes. These can be formulated as follows.

The specific magnetization of the samples $\sigma$ can be described as

$$
\sigma=\phi_{\mathrm{m}, \gamma} \sigma_{\gamma}+\phi_{\mathrm{m}, \mathrm{Ni}} \sigma_{\mathrm{Ni}}+\phi_{\mathrm{m}, \mathrm{Cl}} \sigma_{\mathrm{Cl}}
$$

where $\sigma_{\gamma}, \sigma_{\mathrm{Ni}}$, and $\sigma_{\mathrm{Cl}}$ are specific magnetizations, and $\phi_{\mathrm{m}, \gamma}, \phi_{\mathrm{m}, \mathrm{Ni}}$ and $\phi_{\mathrm{m}, \mathrm{Cl}}$ are the mass fractions of the $\gamma-\mathrm{Fe}_{2} \mathrm{O}_{3}, \mathrm{Ni}_{2} \mathrm{O}_{3}$ and $2 \mathrm{FeCl}_{3} \cdot 5 \mathrm{H}_{2} \mathrm{O}$ phases, respectively. According to the definition of the mass fraction, the relationship between $\phi_{\mathrm{m}, \gamma}, \phi_{\mathrm{m}, \mathrm{Ni}}$ and $\phi_{\mathrm{m}, \mathrm{Cl}}$ is $\phi_{\mathrm{m}, \gamma}+\phi_{\mathrm{m}}$, $\mathrm{Ni}+\phi_{\mathrm{m}, \mathrm{Cl}}=1$. So, formula (1) can be written as

$$
\sigma=\sigma_{\gamma}-\left[\phi_{\mathrm{m}, \mathrm{Ni}}\left(\sigma_{\gamma}-\sigma_{\mathrm{Ni}}\right)+\phi_{\mathrm{m}, \mathrm{Cl}}\left(\sigma_{\gamma}-\sigma_{\mathrm{Cl}}\right)\right]
$$




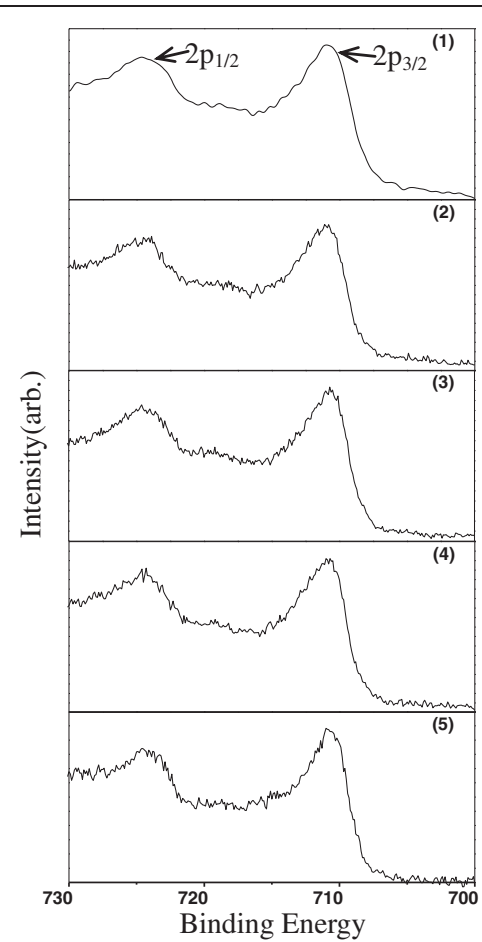

(a)

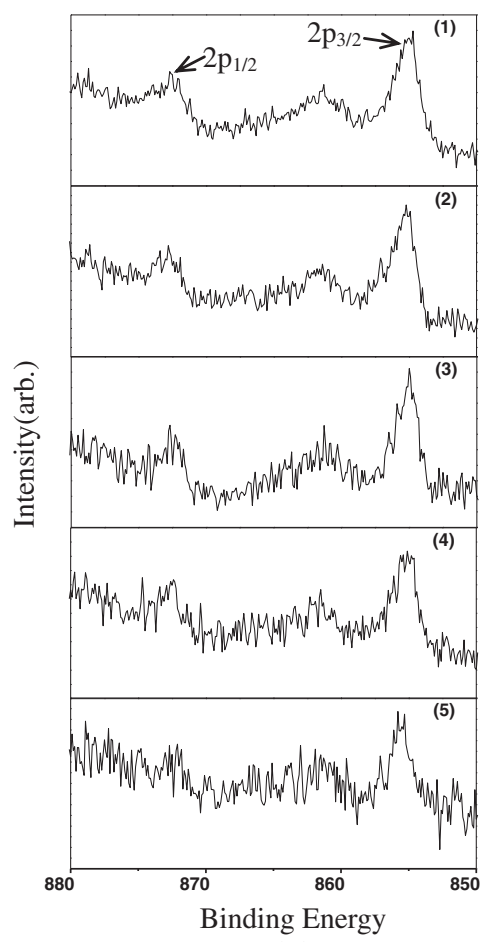

(c)

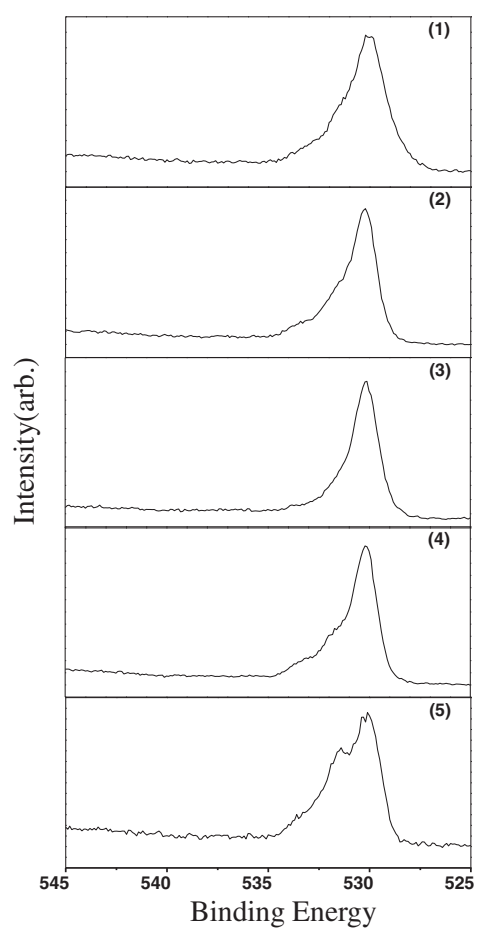

(b)

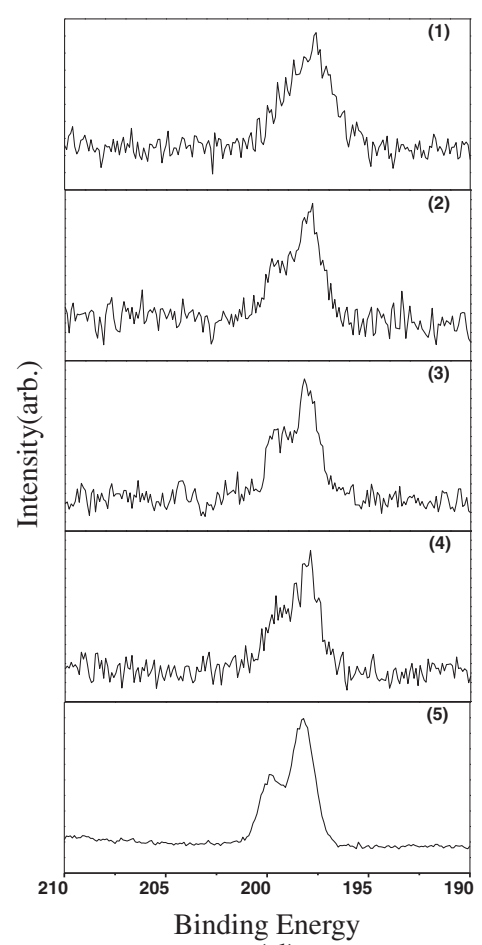

(d)

Figure 5 XPS results: $\mathrm{Fe} 2 \mathrm{p}(\mathrm{a}), \mathrm{O} 1 \mathrm{~s}(\mathrm{~b}), \mathrm{Ni2p}(\mathrm{c})$ and $\mathrm{Cl} 1 \mathrm{~s}(\mathrm{~d})$. 
Table 1 Binding energy data for the elements of the samples from XPS(eV)

\begin{tabular}{lllll}
\hline & $\mathbf{F e 2}_{\mathbf{3} / \mathbf{2}}$ & $\mathbf{0 1 \mathbf { s }}$ & $\mathbf{N i 2}_{\mathbf{3} / \mathbf{2}}$ & $\mathbf{C l 2} \mathbf{p}$ \\
\hline$(1)$ & 710.50 & 530.04 & 854.93 & 197.66 \\
\hline$(2)$ & 710.66 & 530.13 & 855.10 & 197.73 \\
\hline$(3)$ & 710.36 & 530.11 & 854.96 & 198.08 \\
\hline$(4)$ & 710.43 & 530.04 & 855.04 & 197.95 \\
\hline$(5)$ & 710.86 & 530.34 & 855.66 & 198.35 \\
\hline $\mathrm{Fe}_{2} \mathrm{O}_{3}$ & 710.70 & 529.80 & & \\
\hline $\mathrm{Ni}_{2} \mathrm{O}_{3}$ & & 531.80 & 855.60 & \\
\hline $\mathrm{FeCl}_{3}$ & 711.08 & & & 198.72 \\
\hline
\end{tabular}

Note. The standard data for $\mathrm{Fe}_{2} \mathrm{O}_{3}, \mathrm{Ni}_{2} \mathrm{O}_{3}$, and $\mathrm{FeCl}_{3}$ are taken from the HANDBOOK OF X-RAY PHOTOELECTRON SPECTROSCOPY By C. D. Wanger, W. M. Riggs, L. E. Davis, J. F. Moulder, G. E. Muilenberg (Editor).

In addition, the $\phi_{\mathrm{m}, \mathrm{Ni}}$ and $\phi_{\mathrm{m}, \mathrm{Cl}}$ can be described as follows

$$
\begin{aligned}
\phi_{\mathrm{m}, \mathrm{Ni}} & =\frac{\rho_{N i}}{\rho_{N i}-\rho_{C l}+\left[\phi_{v, \gamma}\left(\rho_{\gamma}-\rho_{C l}\right)+\rho_{C l}\right] / \phi_{v, N i}} \\
\phi_{\mathrm{m}, \mathrm{Cl}} & =\frac{\rho_{C l}}{\rho_{C l}-\rho_{N i}+\left[\phi_{v, \gamma}\left(\rho_{\gamma}-\rho_{N i}\right)+\rho_{N i}\right] / \phi_{v, C l}}
\end{aligned}
$$

where $\rho_{\gamma}, \rho_{\mathrm{Ni}}$ and $\rho_{\mathrm{Cl}}$ are the densities, and $\phi_{\mathrm{v},}, \phi_{\mathrm{v}}, \mathrm{Ni}$ and $\phi_{\mathrm{v}, \mathrm{Cl}}$ are the volume fractions of $\gamma-\mathrm{Fe}_{2} \mathrm{O}_{3}, \mathrm{Ni}_{2} \mathrm{O}_{3}$ and $2 \mathrm{FeCl}_{3} \cdot 5 \mathrm{H}_{2} \mathrm{O}$, respectively, and $\phi_{v, \gamma}+\phi_{v, N i}+\phi_{v, C l}=1$. From the experimental results, it is clear that $\phi_{v, \gamma}$ can be regarded as constant for all the samples. Thus, it can be determined from equation (3) that the variations of $\phi_{\mathrm{m}, \mathrm{Ni}}$ and $\phi_{\mathrm{m}, \mathrm{Cl}}$ depend on $\phi_{\mathrm{v}, \mathrm{Ni}}$ and $\phi_{\mathrm{v}, \mathrm{Cl}}$, respectively. In addition, the $\gamma-\mathrm{Fe}_{2} \mathrm{O}_{3}$ is ferrimagnetic, $\mathrm{Ni}_{2} \mathrm{O}_{3}$ is weakly magnetic and $2 \mathrm{FeCl}_{3} \cdot 5 \mathrm{H}_{2} \mathrm{O}$ is paramagnetic, so that the magnetization of the samples depends mainly on the $\gamma-\mathrm{Fe}_{2} \mathrm{O}_{3}$ phase. Therefore, since $\phi_{\mathrm{m}, \mathrm{Ni}}\left(\sigma_{\gamma}-\sigma_{\mathrm{Ni}}\right)>>\phi_{\mathrm{m}}$, $\mathrm{Cl}\left(\sigma_{\gamma}-\sigma_{\mathrm{Cl}}\right)$, equation (2) can be written as

$$
\sigma \cong \sigma_{\gamma}-\left[\phi_{\mathrm{m}, \mathrm{Ni}}\left(\sigma_{\gamma}-\sigma_{\mathrm{Ni}}\right)\right]
$$

So, for concentrations of $\mathrm{FeCl}_{2}$ solution below $0.100 \mathrm{M}$, as the concentration increases from 0.025 to $0.100 \mathrm{M}$, the $\phi_{\mathrm{m}, \mathrm{Ni}}$ (or $\phi_{\mathrm{v}, \mathrm{Ni}}$ ) decreases gradually, so

Table 2 The atomic percentages of $\mathrm{Fe}, \mathrm{O}, \mathrm{Ni}$ and $\mathrm{Cl}$ from XPS measurement and the molar ratio of $\mathrm{Ni203} / \mathrm{FeCl} 3$

\begin{tabular}{lllllllll}
\hline & $\mathbf{F e}$ & $\mathbf{O}$ & $\mathbf{N i}$ & $\mathbf{C l}$ & $\mathrm{Fe}: \mathbf{N i}: \mathbf{C l}$ & $\mathbf{N i}_{\mathbf{2}} \mathbf{O}_{\mathbf{3}} / \mathrm{FeCl}_{\mathbf{3}}$ \\
\hline$(1)$ & 13.79 & 72.50 & 8.56 & 5.15 & 1 & 0.62 & 0.37 & $1 / 0.40$ \\
\hline$(2)$ & 15.48 & 74.94 & 5.88 & 4.58 & 1 & 0.38 & 0.30 & $1 / 0.53$ \\
\hline$(3)$ & 19.21 & 71.06 & 4.15 & 5.58 & 1 & 0.22 & 0.29 & $1 / 0.89$ \\
\hline$(4)$ & 16.74 & 75.45 & 3.11 & 4.70 & 1 & 0.19 & 0.28 & $1 / 1.02$ \\
\hline$(5)$ & 18.71 & 67.21 & 1.84 & 12.25 & 1 & 0.10 & 0.65 & \\
\hline
\end{tabular}



Figure 6 The schematic cross-section of the particle detected by XPS for the samples (1), (2), (3) and (4). Note: $d_{x}<\frac{1}{2} d_{p}$.

that $\sigma$ increases. As long as $\phi_{\mathrm{m}, \mathrm{Ni}}\left(\sigma_{\gamma}-\sigma_{\mathrm{Ni}}\right)<<\phi_{\mathrm{m}, \mathrm{Cl}}$ $\left(\sigma_{\gamma}-\sigma_{\mathrm{Cl}}\right)$, formula (2) can be written as

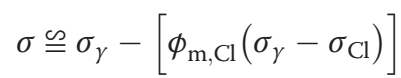

Therefore, for $\mathrm{FeCl}_{2}$ solutions above $0.100 \mathrm{M}$, as the concentration increases from 0.100 to $1.000 \mathrm{M}$, the values of $\phi_{\mathrm{m}, \mathrm{Cl}}\left(\right.$ or $\left.\phi_{\mathrm{v}}, \mathrm{Cl}\right)$ increase so that $\sigma$ is reduced. In addition, it can be deduced that when the concentration of $\mathrm{FeCl}_{2}$ solution is about $0.100 \mathrm{M}$, corresponding to sample(3), perhaps $\phi_{\mathrm{m}, \quad \mathrm{Ni}}\left(\sigma_{\gamma}-\sigma_{\mathrm{Ni}}\right) \cong \phi_{\mathrm{m}, \quad \mathrm{Cl}}\left(\sigma_{\gamma}-\sigma_{\mathrm{Cl}}\right)$, i.e. $\phi_{\mathrm{m}}, \quad \mathrm{Ni} / \phi_{\mathrm{m}}, \quad \mathrm{Cl} \cong\left(\sigma_{\gamma}-\sigma_{\mathrm{Cl}}\right) /\left(\sigma_{\gamma}-\sigma_{\mathrm{Ni}}\right)$, so the specific magnetization $\sigma$ has its maximum value.

\section{Conclusion}

Using a chemically induced transition, $\mathrm{Ni}_{2} \mathrm{O}_{3}-\gamma-\mathrm{Fe}_{2} \mathrm{O}_{3}$ bioxide composite nanoparticles can be prepared using $\mathrm{FeCl}_{2}$ solutions with different concentrations. Using a number of characterization tools, such as VSM, XRD, TEM and XPS, the dependence of the samples on the concentration of the $\mathrm{FeCl}_{2}$ solution has been revealed. When the $\mathrm{FeCl}_{2}$ concentration was less than $0.500 \mathrm{M}$, the samples consisted of spherical $\mathrm{Ni}_{2} \mathrm{O}_{3}-\gamma-\mathrm{Fe}_{2} \mathrm{O}_{3}$ particles, about $11 \mathrm{~nm}$ diameter, coated with $2 \mathrm{FeCl}_{3} \cdot 5 \mathrm{H}_{2} \mathrm{O}$. When the $\mathrm{FeCl}_{2}$ concentration was $0.500 \mathrm{M}$, the product consisted of both $\mathrm{Ni}_{2} \mathrm{O}_{3}-\gamma-\mathrm{Fe}_{2} \mathrm{O}_{3}$ spherical particles, of about $8 \mathrm{~nm}$ size, and $2 \mathrm{FeCl}_{3} \cdot 5 \mathrm{H}_{2} \mathrm{O}$ rod-shaped particles. Nevertheless, the size of the $\gamma-\mathrm{Fe}_{2} \mathrm{O}_{3}$ grains was about the same for all samples. Significantly, the magnetization of the samples exhibited a non-monotonic variation although the ratio between the $\mathrm{Ni}$ and $\mathrm{Cl}$ species decreased monotonically with the increasing concentration of the $\mathrm{FeCl}_{2}$ solution. It was noticed that samples prepared using $\mathrm{FeCl}_{2}$ solutions with concentrations 
$0.025 \mathrm{M} 0.075 \mathrm{M}, 0.100 \mathrm{M}$ and $0.125 \mathrm{M}$, have the same size particles, about $11 \mathrm{~nm}$, and same size of $\gamma-\mathrm{Fe}_{2} \mathrm{O}_{3}$ grains, about $8 \mathrm{~nm}$. Therefore, it is deduced that the variation of the apparent magnetization has resulted from the competition between the reduced $\mathrm{Ni}_{2} \mathrm{O}_{3}$ phase and increasing $2 \mathrm{FeCl}_{3} \cdot 5 \mathrm{H}_{2} \mathrm{O}$. When the concentration of $\mathrm{FeCl}_{2}$ solution does not exceed $0.100 \mathrm{M}$, the magnetization of the samples increases with increasing concentration since the rate of reduction of $\mathrm{Ni}_{2} \mathrm{O}_{3}$ is larger than the increase of $2 \mathrm{FeCl}_{3} \cdot 5 \mathrm{H}_{2} \mathrm{O}$. When the $\mathrm{FeCl} 2$ concentration exceeds $0.100 \mathrm{M}$, the magnetization of the samples weakens since the increase of $2 \mathrm{FeCl}_{3} \cdot 5 \mathrm{H}_{2} \mathrm{O}$ is now larger than the decrease of $\mathrm{Ni}_{2} \mathrm{O}_{3}$. Therefore, it can be concluded that using the chemically induced transition method to prepare $\mathrm{Ni}-\mathrm{Fe}$ bioxide composite nanoparticles, as long as the concentration of the $\mathrm{FeCl}_{2}$ solution does not exceed $0.100 \mathrm{M}$, the thickness of both $\mathrm{Ni}_{2} \mathrm{O}_{3}$ and $2 \mathrm{FeCl}_{3} \cdot 5 \mathrm{H}_{2} \mathrm{O}$ layers can be controlled and the $\gamma-\mathrm{Fe}_{2} \mathrm{O}_{3}$ core size remains constant. As a result, magnetic nanoparticles with a fixed size of about $11 \mathrm{~nm}$ but different magnetization can be obtained.

\section{Competing interests}

Non-financial competing interests.

\section{Authors' contributions}

All authors contributed equally to this work. All authors read and approved the final manuscript.

\section{Acknowledgements}

Financial support for this work was provided by the National Science Foundation of China (No.11074205).

Received: 26 July 2012 Accepted: 12 October 2012

Published: 30 October 2012

\section{References}

1. Pankhrust QA, Connolly J, Jones SK, Dobson J: Application of magnetic nanoparticles in biomedicine. J. Phys. D 2003, 36:R167-R181.

2. Willard MA, Kurihara LK, Carpenter EE, Calvin S, Harris VG: Chemically prepared magnetic nanoparticles. Inter. Mater. Rev. 2004, 49(3/4):125-170.

3. Sun S: Recent advance in chemical synthesis, self-assembly, and applications of FePt nanoparticles. Adv Mater 2006, 18:393-403.

4. Lin CR, Wang CC, Chen IH: Magnetic behavior of core-shell particles. J. Magn. Magn. Mater. 2006, 304:e34-e36.

5. Jiang J, Yang YM: Facile synthesis of nanocrystalline spinel $\mathrm{NiFe}_{2} \mathrm{O}_{4}$ via a novel soft chenistry route. Mater Lett 2007, 61:4276-4279.

6. Szabo DV, Vollath D: Nanocomposites from coated nanoparticles. Adv Mater 1999, 11:1313-1316.

7. Liu J, Qiao SZ, Hu QH, Lu GQ: Magnetic nanocomposites with mesoporous structures: synthesis and application. Small 2011, 7:425-443.

8. Lu Y, Yin Y, Mayers BT, Xia Y: Modifying the surface properties of superparamagnetic iron oxide nanoparticles through a sol-gel approach. NanoLett. 2002, 2:183-186.

9. Donselaar LN, Philips AP, Suurmoned J: Concentration-dependent sedimentation of dilute magnetic fluids and magnetic silica dispersions. Langmuir 1997, 13:6018-6025.

10. Duarte MA, Giersig M, Kotov NA, Marzan LML: Control of packing order of self-assembed monolayers of magnetic nanoparticles with and without $\mathrm{SiO}_{2}$ coating by microwave irradiation. Langmuir 1998, 14:6430-6435.

11. Butterworln MD, Illum L, Davis SS: Preparation of ultrafine silica-and-PEGcoated magnetic particles. Colloid Sur. A 2001, 179:93-102

12. Kawaguchi K, Jaworski J, Ishikawa Y, Sasaki T, Koshizaki N: Preparation of gold/iron-oxide composite nanoparticles by a unique laser process in water. J. Magn. Magn. Mater. 2007, 310:2369.
13. Yuvaraj $\mathrm{H}$, Woo MH, Park EJ, Jeong $Y T$, Lim KT: Polypyrrole/ $/ \mathrm{Y}-\mathrm{Fe}_{2} \mathrm{O}_{3}$ magnetic nanocomposites synthesized in supercitical fluid. Eur Polym J 2008, 44:637-644.

14. Xu XJ, Wang J, Yang CQ, Wu HY, Yang FF: Sol-gel formation of $\mathrm{Y}-\mathrm{Fe}_{2} \mathrm{O}_{3}$ l $\mathrm{SiO}_{2}$ nanocomposites: Effects of different iron raw material. $J$ Alloys Compd 2009, 468:414-420.

15. Zhang QM, Li J, Lin YQ, Liu YD, Miao H: The spreparation and characterization of NI-Fe bioxide composite nanoparticles. J. Alloys Comp. 2010, 508:396-399

16. Zhang QM, Li J, Miao H, Fu J: Preparation of $\mathrm{y}-\mathrm{Fe}_{2} \mathrm{O}_{3} / \mathrm{Ni}_{2} \mathrm{O}_{3} / \mathrm{FeCl}_{3}\left(\mathrm{FeCl}_{2}\right)$ composite nanoparticles by hydrothermal process useful for ferrofluids. Smart Mater Res 2011, DOI:10.1155/2011/35/072 (page number not for citation purposes).

17. Liu $Q, X u Z$, Finch $J A$, Egerton R: A novel two-step silica-coating process for engineering magnetic nanocomposites. Chem Mater 1998, 10:3936-3940

18. Wen $B C$, Li J, Lin YQ, Liu XD, Fu J, Miao H, Zhang QM: A novel preparation method for $\gamma-\mathrm{Fe}_{2} \mathrm{O}_{3}$ nanoparticles and their characterization. Mater. Chemi. Phys. 2011, 128:35-38,

19. Miao $\mathrm{H}$, Li J, Lin YQ, Liu XD, Zhang QM, Fu J: Characterization of $\mathrm{Y}-\mathrm{Fe}_{2} \mathrm{O}_{3}$ nanoparticles prepared by transformation of a-FeOOH. Chinese Sci. Bull. 2011, 56:2383-2388.

20. $L$ in $L H, L i J$, Fu J, Lin YQ, Liu XD: Preparation, magnetization, and microstructure of ionic ferrofluids based on $\mathrm{Y}^{-} \mathrm{Fe}_{2} \mathrm{O}_{3} / \mathrm{Ni}_{2} \mathrm{O}_{3}$ composite nanoparticles. Mater. Chemi. Phys. 2012, 134:407-411.

21. Li J, Lin YQ, Liu XD, Zhang QM, Miao H, Zhang TZ, Wen BC: The study of transition on $\mathrm{NiFe}_{2} \mathrm{O}_{4}$ nanoparticles prepared by co-precipitation/ calcinations. Phase Trans. 2011, 84:49-57.

22. Iwacaki T, Kosaka K, Watano S, Yanagida T, Kawai T: Novel environmentally friendly synthesis of superparamagnetic magnetite nanoparticles using mechanochemical effect. Mater Res Bull 2010, 45:481-485.

23. Srnová-Šloufová I, VIcková B, Bastl Z, Hasslet TL: Bimetallic (Ag) Au nanoparticles prepared by the seed growh: Two-dimensional assembling, characterization by energy disperse $\mathrm{X}$-ray analysis. X-ray photoelectron spectroscopy, and surface enhanced Raman Spectroscopy, and proposed mechanism of growth, Langmuir 2004, 20:3407-3415.

24. Tanuma S, Powell CJ, Penn DR: Calculations of electron inelastic mean free paths. Surf Interface Anal 1991, 17:911-926.

doi:10.1186/1752-153X-6-127

Cite this article as: Lin et al:: The dependence of Ni-Fe bioxide composites nanoparticles on the $\mathrm{FeCl}_{2}$ solution used. Chemistry Central Journal 2012 6:127 